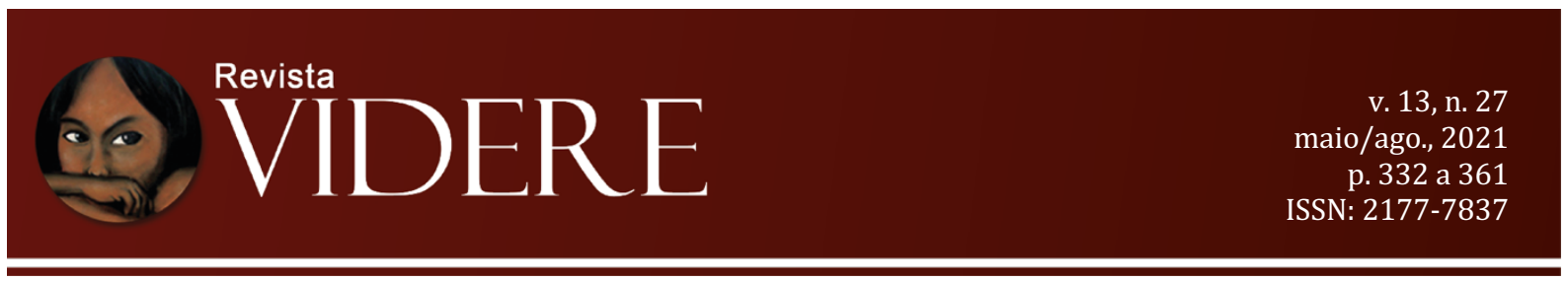

\title{
PROTEÇÃO DO TRABALHO DAS PESSOAS COM DEFICIÊNCIA NO ÂMBITO INTERNACIONAL: [DES]CONEXÕES ENTRE ORGANIZAÇÃO INTERNACIONAL DO TRABALHO E O COMITÊ INTERNACIONAL SOBRE OS DIREITOS DAS PESSOAS COM DEFICIÊNCIA
}

\author{
PROTECTION OF THE WORK OF PERSONS WITH DISABILITIES IN \\ INTERNATIONAL LEVEL: [MIS]CONNECTIONS BETWEEN THE INTERNATIONAL \\ LABOR ORGANIZATION AND THE UN COMITEE ON THE RIGHTS OF PERSONS \\ WITH DISABILITIES
}
PROTECCIÓN DEL TRABAJO DE LAS PERSONAS CON DISCAPACIDAD A NIVEL INTERNACIONAL: [DES]CONEXIONES ENTRE LA ORGANIZACIÓN INTERNACIONAL DEL TRABAJO Y EL COMITE DE LA ONU SOBRE LOS DERECHOS DE LAS PERSONAS CON DISCAPACIDAD

Laís Teixeira Barbosa Sak Mestre em Direito Humanos e Cooperação Internacional Pontifícia Universidade Católica de Campinas - PUC Campinas laistbarbosa@gmail.com https://orcid.org/0000-0003-2545-9478

Pedro Pulzatto Peruzzo Professor Doutor Pontifícia Universidade Católica de Campinas - PUC Campinas https://orcid.org/0000-0001-5270-8674 pedro.peruzzo@puc-campinas.edu.br

Silvio Beltramelli Neto Professor Doutor Pontifícia Universidade Católica de Campinas - PUC Campinas https://orcid.org/0000-0002-3940-5983 silviobeltramelli@gmail.com

\begin{abstract}
Resumo: Apesar de a Organização Internacional do Trabalho (OIT) ter dedicado grande atenção ao tema do Trabalho Decente desde o ano 2000, esta não tem feito alusão às pessoas com deficiência (PcDs) nos principais documentos internacionais sobre este tema, sendo, pois, "Trabalho Decente" e "pessoas com deficiência" tratados reiteradamente em agendas distintas. Em 2020, um documento da OIT sobre condições de trabalho das PcDs durante a pandemia ocasionada pelo COVID-19 foi embrionário neste sentido por aludir que as decisões no momento de pandemia repercutiriam no acesso de tais pessoas ao Trabalho Decente. Considerando o compromisso de cooperação internacional e, especialmente, as diversas orientações do Comitê Internacional sobre Direitos das Pessoas com Deficiência (Comitê),
\end{abstract}


criado pela ONU em 2007, acerca do direito ao trabalho e emprego das PcDs, analisar-se-á se é possível afirmar que há alguma convergência entre as orientações da OIT e do Comitê em relação ao Trabalho Decente para as PcDs. Foram empregados os métodos hipotético-dedutivo e documental (análise qualitativa), sendo assumida como hipótese a inexistência de convergência conceitual entre os dois organismos internacionais quanto à promoção do Trabalho Decente. $\mathrm{O}$ trabalho analisa vários documentos destes organismos sobre "Trabalho Decente", "trabalho e PcDs", incluindo convenções, declarações e outros documentos, bem como o diretório "jurisprudência do Comitê". Embora os organismos possuam expressões diferentes, conclui-se que há certa convergência entre ambos para promover condições dignas de trabalho às $\mathrm{PcDs}$, mas falta interação para mútuo conhecimento das barreiras enfrentadas pelas PcDs no trabalho.

Palavras-chave: Direitos Humanos. Cooperação Internacional. Organização Internacional do Trabalho. Comitê Internacional sobre os Direitos das Pessoas com Deficiência da ONU. Trabalho decente.

Abstract: Although the International Labor Organization (ILO) has devoted great attention to the topic of Decent Work since 2000, it has not addressed persons with disabilities (PwDs) in the main international documents on this topic, being, therefore, "Decent Work" and "persons with disabilities" repeatedly treated in different agendas. In 2020, an ILO document on the working conditions of PwDs during the pandemic caused by COVID-19 was embryonic in this sense, as it alluded that decisions at the time of the pandemic would have an impact on these people's access to Decent Work. Considering the commitment to international cooperation and, in particular, the various guidelines of the International Committee on the Rights of Persons with Disabilities (Committee), created by the UN in 2007 regarding the right to work and employment of PwDs, this paper will analyze whether it is possible to affirm that there is some convergence between the ILO and the Committee's guidelines regarding Decent Work for PwDs. The hypothetical-deductive and documentary methods (qualitative analysis) were used, assuming as a hypothesis the lack of conceptual convergence between the two international organizations regarding the promotion of Decent Work. The paper analyzes many documents of these bodies on "Decent Work", "work and PwDs", including conventions, declarations and other documents, as well as the jurisprudence of the Committee. Although both have different expressions, it is possible to conclude that there is a certain convergence between both to promote decent working conditions for PwDs, but there is a lack of interaction for mutual knowledge of the barriers faced by PwDs at work.

Keywords: Human rights. International Cooperation. International Labor Organization. UN Committee on the Rights of Persons with Disabilities. Decent work.

Resumen: Aunque la Organización Internacional del Trabajo (OIT) ha dedicado gran atención al tema del Trabajo Decente desde el año 2000, no ha abordado a las personas con discapacidad (PcDs) en los principales documentos internacionales sobre este tema, siendo, por tanto, "Trabajo Decente" y "personas con discapacidad" consideradas reiteradamente en diferentes agendas. En 2020, un documento de la OIT sobre las condiciones laborales de las personas con discapacidad durante la pandemia provocada por la COVID-19 fue sucinto en este sentido, ya que aludía a que las decisiones tomadas en el momento de la pandemia repercutirían en el acceso de estas personas al Trabajo Decente. Teniendo en cuenta el compromiso con la cooperación internacional y, en particular, las distintas directrices del Comité Internacional de los Derechos de las Personas con Discapacidad (Comité), creado por la ONU en 2007 sobre el derecho al trabajo y empleo de las personas con discapacidad, en este trabajo se analizará si es posible afirmar que existe cierta convergencia entre la OIT y las directrices del Comité sobre Trabajo Decente para Personas con discapacidad. Se utilizaron los métodos hipotéticodeductivo y documental (análisis cualitativo), asumiendo como hipótesis la falta de convergencia conceptual entre los dos organismos internacionales en materia de promoción del Trabajo Decente. El documento analiza muchos documentos de estos órganos sobre "Trabajo Decente", "Trabajo y Personas con Discapacidad", incluyendo convenciones, declaraciones y otros documentos, así como la jurisprudencia del Comité. Si bien ambos tienen expresiones diferentes, es posible concluir que existe alguna convergencia entre ambos para promover condiciones de trabajo dignas para las personas con 
discapacidad, pero hay una falta de interacción para el conocimiento mutuo de las barreras que enfrentan las personas con discapacidad en el trabajo.

Palabras clave: Derechos humanos. Cooperación internacional. Organización Internacional del Trabajo. Comité de las Naciones Unidas sobre los derechos de las personas con discapacidad. Trabajo decente.

\section{Introdução ${ }^{1}$}

Este trabalho visa analisar se há, no âmbito da cooperação internacional para a proteção do trabalho das pessoas com deficiência $(\mathrm{PcDs})^{2}$, uma convergência conceitual das ações da Organização Internacional do Trabalho (OIT) sobre Trabalho Decente e do Comitê sobre os Direitos das Pessoas com Deficiência (PcDs) da Organização das Nações Unidas (Comitê), criado em 2007 pela Convenção Internacional de Direitos das PcDs da ONU (CIDPCD), acerca o direito ao trabalho e emprego das PcDs (artigo 27, CIDPCD). Apesar de distintos, ambos contêm normas e orientações sobre o direito ao trabalho das PcDs. Resta identificar se possuem convergência conceitual à definição estratégica da proteção do Trabalho Decente destas pessoas, com algum conteúdo vinculante aos Estados membros.

No âmbito da OIT, as principais normas internacionais aplicáveis às PcDs são as seguintes: (i) a Convenção Internacional n 111 de 1948 sobre "Discriminação em Matéria de Emprego e Ocupação", que não menciona PcDs expressamente; e (ii) a Convenção Internacional no 159 de 1983 sobre "Reabilitação Profissional e Emprego de Pessoas Deficientes", cujo foco é empregabilidade (admissão) das PcDs. Desde 1999, a OIT adotou o Trabalho Decente como eixo central de suas ações (VOSKO, 2002), buscando conferir condições dignas a qualquer tipo de trabalho. Embora a OIT não tenha definido "Trabalho Decente" de forma fechada, a literatura reconhece-o amparado no marco da teoria das capacidades de Amartya Sen, que serviu também de fundamento teórico ao Programa das Nações Unidas para o Desenvolvimento em prol da promoção do Desenvolvimento Humano e consequente criação do Índice de Desenvolvimento Humano (IDH).

As citadas convenções e concepção de Trabalho Decente advieram na vigência do modelo médico de deficiência, segundo o qual a classificação de uma pessoa como deficiente deveria ser definida exclusivamente a partir de sua deficiência funcional - por exemplo, de

\footnotetext{
${ }^{1}$ Agradecemos aos editores e aos avaliadores pela leitura cuidados e atenta do texto. As recomendações e críticas foram fundamentais para o aprimoramento do trabalho.

${ }^{2} \mathrm{O}$ trabalho referenciará, de forma abreviada, "pessoa com deficiência" (no singular) como "PcD", e "pessoas com deficiência" (no plural) como "PcDs". 
acordo com sua acuidade visual ou déficit intelectual. Este modelo foi criticado por tratar a deficiência como uma patologia atribuída à pessoa, ou seja, por reconhecer como deficiente a pessoa que tenha ou porte alguma deficiência reconhecida pela lei como tal a partir de um rol taxativo. Este modelo médico estimula programas de cura e reabilitação das deficiências (MITRA, 2006), contudo, deixa de considerar as barreiras de toda natureza criadas pela própria sociedade às PcDs, bem como que tipos de deficiência não normatizados sejam protegidos.

Superando o modelo médico, a CIDPCD consignou em 2007, internacionalmente, uma abordagem social ao modelo de deficiência, pelo qual se atribui também à sociedade uma corresponsabilidade sobre a construção da deficiência. Em síntese, por este novo modelo, considera-se a deficiência resultante da conjugação da deficiência per se (aspectos médicos propriamente ditos) com uma construção social ${ }^{3}$. O Comitê refere-se a este novo modelo como "modelo de deficiência da Convenção" embora parte da literatura use "modelo biopsicossocial"4. À luz deste, uma pessoa completamente cega é considerada deficiente por sua incapacidade visual e inexistência de recursos que possam reverter seu quadro médico (como cirurgia corretiva) e, de outro, em razão de uma construção social que a impede de vivenciar as mesmas experiências e ter as mesmas condições de qualidade de vida que as demais pessoas que não sejam deficientes - por exemplo, porque a sociedade não the proporciona condições adequadas para se locomover sozinha para o trabalho, ou porque o recrutador o considera menos capacitado como trabalhador em razão desta deficiência.

A CIDPCD, se faz acompanhar de um Protocolo Facultativo, pelo qual os Estados podem reconhecer a competência do Comitê de Direitos das PcDs para, dentre outras atribuições, analisar casos concretos de violações dos direitos das PcDs. De acordo com o artigo

\footnotetext{
${ }^{3}$ A abordagem social de deficiência da deficiência permeia toda a Convenção, ficando clara através das barreiras abordadas. Isso é notável, por exemplo, no artigo $1^{\circ}$ pela qual define as PcDs como as pessoas que têm "impedimentos de longo prazo de natureza física, mental, intelectual ou sensorial, os quais, em interação com diversas barreiras, podem obstruir sua participação plena e efetiva na sociedade em igualdades de condições com as demais pessoas".

${ }^{4} \mathrm{~A}$ análise sobre os aspectos teóricos adotados pela CIDPCD exigiria um trabalho apartado. De forma resumida, há um modelo social de deficiência originário da Grã-Bretanha (década de 1970) que passou a defender que a deficiência não teria nenhuma relação com o fator médico, mas seria resultado exclusivo de uma construção da própria sociedade na medida em esta cria barreiras em torno da deficiência (a exemplo da discriminação). Conforme KAZOU (2017, p.47), durante as tratativas de elaboração da CIDPCD, como esta vertente radical exclui o fator médico, entendeu-se que poderia dar margem para que os Estados se esquivassem de garantir o acesso de PcDs à tratamentos médicos. A CIDPCD teria, pois, adotado um modelo híbrido ao incorporar a abordagem social (social approach). A literatura nacional usa "modelo biopsicossocial" como sinônimo deste, já que dentro do fator social proposto pelo movimento acima, são consideradas as barreiras criadas pela sociedade e suas consequências no plano psicológico. Com base nas decisões do Comitê, entende-se que este tem, na prática, rejeitado o modelo médico (porque repudia que se considere apenas critérios médicos taxativos para definir o que é deficiência) e tem considerado os parâmetros biopsicossociais para suas análises, embora não faça referência ao termo. Seguimos a nomenclatura adotada pelo Comitê por acuidade metodológica.
} 
38 da Convenção, o Comitê poderá solicitar à cooperação de outros órgãos da ONU para suas decisões - o que permite solicitar a cooperação da OIT.

No ano de 2015, os Estados-membros da ONU definiram a Agenda 2030, pelo qual se comprometeram a promover, até 2030, dentre outros, o Trabalho Decente (oitavo objetivo, em que não há referência à $\mathrm{PcDs}$ ) e incluir as $\mathrm{PcDs}$ (décimo objetivo). Embora não seja um tratado internacional, demonstra a clara intenção dos Estados de atingir estes objetivos especificamente, conquanto definidos de forma apartada um do outro. Nesse sentido, com base em documentos da OIT e do Comitê, percebeu-se um hiato no discurso internacional da ONU sobre trabalho de PcDs: de um lado, desde 1999, a OIT tem propagado "Trabalho Decente", porém, sem referência expressa à proteção do Trabalho Decente das PcDs em documentos de hard law; de outro, nos casos envolvendo direito ao trabalho levados ao Comitê, não há referência a Trabalho Decente nas manifestações das vítimas e do órgão de monitoramento.

A investigação tem relevância social. Segundo a OMS, há mais de 1 bilhão de pessoas com deficiência moderada a alta, correspondendo a 15,6\% da população mundial (OMS, 2011, p.51). Embora inexistam indicadores globais sobre trabalho das PcDs, os dados internos dos Estados indicam que estas enfrentam diferentes oportunidades de trabalho. Por exemplo, no Brasil, de acordo com o Relatório de Avaliação de Informações Sociais (RAIS) de 2017, apenas $0,9 \%$ dos postos de trabalho formal foram ocupados por PcDs e estas têm salários inferiores às demais pessoas (BRASIL, RAIS, 2018).

O problema abordado foi: "há uma convergência conceitual entre a OIT e o Comitê sobre Direitos das Pessoas com Deficiência da ONU à promoção do Trabalho Decente às PcDs?". Para a investigação, foram considerados o estado-da-arte dos diretórios da Scielo e Scopus ${ }^{5}$, e documentos da OIT e do Comitê, todos com recorte do período entre 2015 a 2020, referentes ao tema de trabalho e emprego das PcDs. Foi empregado o método de abordagem hipotético-dedutivo, tendo como hipótese que a inexistência de convergência entre a OIT e o Comitê na promoção do Trabalho Decente tem por consequência o desemparo fático e jurídico das PcDs quanto à sua condição de sujeitos de políticas e direitos ao Trabalho Decente.

\footnotetext{
${ }^{5}$ Buscou-se apenas produções científicas públicas em Qualis B1 e acima. Apenas 2 resultados relacionaram Trabalho Decente e PcDs, e outros 12 referenciaram Trabalho Decente à luz de Amartya Sen. Consideramos os seguintes descritores de forma cumulativa, referenciados no título ou no resumo: (i) "Trabalho Decente"; "OIT" ou "Organização Internacional do Trabalho"; "PcDs" ou "Pessoas com Deficiência"; (ii) Trabalho Decente"; "Comitê" ou "Comitê de Direitos das Pessoas com Deficiência"; "PcDs" ou "Pessoas com Deficiência"; "Trabalho Decente"; PcDs" ou "Pessoas com Deficiência" (i.e., excluindo-se a OIT e o Comitê); e (iv) "PcD” e "Amartya Sen". Para fins de esclarecimento, pesquisou-se sobre a conexão entre PcDs e Amartya Sen, já que a teoria das capacidades promovida por este autor foi basilar para a concepção de Trabalho Decente. 
Procedimentalmente, foi empregado o método documental pela avaliação análise qualitativa dos documentos da OIT e do Comitê.

\section{Trabalho decente e o trabalho das PcDs no âmbito da OIT}

A OIT foi criada em 1919 pelo Tratado de Versalhes, após Primeira Guerra Mundial (ABRAMO, 2010, p. 151), com o objetivo geral de proteger direitos relações de trabalho. É a única organização internacional com composição tripartite, ou seja, por representantes dos Estados-membros (governos), do mercado (empregadores), e dos trabalhadores (DAELE, 2002, p. 1-3).

Em 1958, a OIT aprovou a Convenção n 111 sobre "Discriminação em Matéria de Emprego e Ocupação". Apesar de não fazer referência à discriminação contra PcDs, seu artigo 1..$^{\circ}$ tem conteúdo amplo e considera como discriminatória qualquer distinção que tenha por efeito destruir ou alterar a igualdade de oportunidades em matéria de emprego. Em 1983, a OIT aprovou a Convenção n 159 sobre "Reabilitação Profissional e Emprego de Pessoas Deficientes". Em síntese, a Convenção n ${ }^{\circ} 159$ tenta promover a igualdade de oportunidades entre "trabalhadores deficientes" e trabalhadores em geral e determina como mandatória a adoção de tratamento igualitário aos mesmos. Tem um conteúdo genérico sobre integração de deficientes no trabalho, porquanto determina que os Estados-membros devem promover a igualdade de oportunidades, porém não cria mecanismos específicos para tanto. Ou seja, não é possível depreender desta convenção quais seriam as condições que os Estados membros deveriam promover para um ambiente integrativo às PcDs. Filia-se ao modelo médico da deficiência, o que é perceptível a partir do Preâmbulo e dos artigos 1 e 2 em razão de dois elementos: em primeiro lugar, define "pessoa deficiente" com base apenas na deficiência médica, sem qualquer referência ao papel da sociedade na construção da deficiência (artigo 1); em segundo lugar, considera que o trabalho seria um meio pelo qual a PcD poderia se integrar na sociedade - ao invés de propor formas de como a sociedade, inclusive no ambiente do trabalho, poderia incluí-las, como propõe a CIDPCD. O modelo médico de defíciência está associado ao objetivo de integração que implica na normalização ou retificação da pessoa ao invés de aceita-la como ela é. Neste modelo, a PcD teria a responsabilidade de superar suas dificuldades e obter cura e tratamento de sua deficiência, de modo que assim tenha condições de ser considerada "normal" pela sociedade e seja apta a integrar-se com os demais. A inclusão, ao revés, compreende o reconhecimento da deficiência como uma diferença e permite, pois, 
que a sociedade possa reconhecer a PcD como parte da sociedade exatamente como ela é (FREITAS e MARQUES, 2007, p. 73) ${ }^{6}$.

Em 1998, a OIT elaborou a Declaração sobre os Princípios e Direitos Fundamentais do Trabalho ("Declaração"). Apesar de ser um mecanismo de soft law (VOSKO, 2002, p. 28), a Declaração traz 4 princípios fundamentais, que viriam a fundamentar a concepção oficialmente acatada de Trabalho Decente, quais sejam: (i) liberdade sindical e o reconhecimento efetivo do direito de negociação coletiva; (ii) a eliminação de todas as formas de trabalho forçado ou obrigatório; (iii) a abolição efetiva do trabalho infantil; e (iv) a eliminação da discriminação em matéria de emprego e ocupação. Este último é o princípio com maior conexão com as PcDs, já que a discriminação em matéria de emprego e ocupação é recorrente reclamação ao Comitê, como será detalhado no item subsequente.

A primeira referência a Trabalho Decente foi feita no fim da década de 1990, quando o cenário internacional era de exacerbação do liberalismo econômico, acelerado pela força do capital financeiro globalmente desregulamentado, o que culminou no desequilíbrio entre proteção normativa e concreção de direitos humanos frente ao desenvolvimento do mercado "cuja precariedade é, justamente, base ao avanço de um capitalismo frenético, possessivo e indecente" (JULIOS-CAMPUZANO, 2008, p. 58). Naquele cenário, com a globalização de problemas que evidenciavam a precariedade do trabalho (trabalho infantil e escravo), gradativamente começou-se a edificar noções de Trabalho Decente no âmbito da OIT (COSTA e DIEHL, 2016). A primeira referência à "Trabalho Decente" foi feita pelo então Diretor Geral da OIT em 19997, pelo qual se entende que o Trabalho Decente abrange liberdade, equidade, segurança e dignidade humana, do qual se depreendem 4 objetivos estratégicos: (i) a proteção dos direitos humanos nas relações de trabalho, (ii) a geração de mais e melhores

\footnotetext{
${ }^{6}$ A definição de "pessoa deficiente" da Convenção OIT n ${ }^{\circ} 159$ de 1983 é dada a partir exclusivamente da deficiência, sem considerar que a própria sociedade contribui para a exclusão das PcDs. Além disso, o propósito deste Convenção é a "integração ou a reintegração" das PcDs, que difere do modelo biopsicossocial cujo objetivo é a inclusão conforme acima (FREITAS e MARQUES, 2007). Neste sentido: "Art. 1 - 1. Para efeitos desta Convenção, entende-se por 'pessoa deficiente' todas as pessoas cujas possibilidades de obter e conservar um emprego adequado e de progredir no mesmo fiquem substancialmente reduzidas devido a uma deficiência de caráter físico ou mental devidamente comprovada"; e "Art. 2. Para efeitos desta Convenção, todo o País-Membro deverá considerar que a finalidade da reabilitação profissional é a de permitir que a pessoa deficiente obtenha e conserve um emprego e progrida no mesmo, e que se promova, assim a integração ou a reintegração dessa pessoa na sociedade".

${ }^{7}$ Indicando sua concepção de Trabalho Decente, o então Diretor Geral da OIT proferiu a seguinte fala na $87^{\mathrm{a}}$ Reunião da Conferência Internacional do Trabalho na cidade de Genebra em 1999: "Atualmente, a finalidade primordial da OIT é promover oportunidades para que homens e mulheres possam conseguir um trabalho decente e produtivo em condições de liberdade, equidade, segurança e dignidade humanas [...] $\mathrm{O}$ trabalho decente é o ponto de convergência de quatro objetivos estratégicos: a promoção dos direitos fundamentais no trabalho, o emprego, a proteção social e o diálogo social. Isso deve orientar as decisões da Organização e definir sua tarefa internacional nos próximos anos. (CONFERÊNCIA INTERNACIONAL DEL TRABAJO, 1999).
} 
empregos para homens e mulheres, (iii) a extensão da proteção social; e (iv) promoção do tripartidíssimo e dialogo social (ABRAMO, 2010, p. 151). No entanto, sua consagração era ainda incipiente, o que se pode evidenciar pela ausência de menção dentre os Objetivos de Desenvolvimento do Milênio em 2000 (ONU, 2000).

A OIT vem, desde então, fazendo uso do Trabalho Decente com seu eixo temático central de atuação, ainda que, para tanto, tenha, propositalmente, prescindido de uma definição cerrada. Ao contrário, a OIT propõe o Trabalho Decente como uma concepção maleável quanto ao conteúdo, um dos traços denotadores da inspiração anunciada na teoria das capacidades de Amartya Sen $\left(2000 ; 200^{a}\right)$, substrato da noção de desenvolvimento humano, adotada pelo Programa das Nações Unidas para o Desenvolvimento (PNUD) da ONU, na década de $1980^{8}$.

Sen desenvolveu diversos trabalhos no Banco Mundial partido da premissa de que o desenvolvimento não se alcança apenas com crescimento econômico, mas sobretudo pela ampliação das capacidades dos indivíduos e, consequentemente, de suas liberdades, as quais, ao fim e ao cabo, convergem para que toda pessoa possa expandir o leque de escolhas para sua própria vida, segundo suas avaliações e interesses. Nesse sentido, o desenvolvimento expande as liberdades das pessoas (liberdade formal e concreta, abrangendo também o acesso ao trabalho) que, por sua vez, culmina em maior desenvolvimento humano. Sen propõe que, de um lado, as próprias liberdades promovem o desenvolvimento e, de outro, o resultado deste importará na própria expansão das liberdades. Como corolário, o ciclo promove a emergência, nas pessoas, da capacidade de "agência", isto é, de promoção de mudanças na sociedade.

Portanto, as liberdades têm um papel constitutivo (como fim primordial do desenvolvimento) e um papel instrumental (como principal meio do desenvolvimento). Há, ainda, liberdades concomitantemente constitutivas e instrumentais (SEN, 2000a, p.36). Em ambos os papéis, a liberdade não deve ser entendida exclusivamente como o direito à liberdade (e suas diversas espécies); diferentemente, o autor propõe que o desenvolvimento de um país pode levar a população menos favorecida à liberdade, no sentido de uma melhor qualidade de vida e meios de exercer seus direitos fundamentais. O desenvolvimento, sob tal prisma, é um “processo de expansão das liberdades reais que as pessoas desfrutam” (SEN, 2000a, p. 52).

O ponto nuclear da teoria seniana é o desenvolvimento humano. E, nesse sentido, para Sen (2000, p.75), este desenvolvimento deve ser avaliado de acordo com as funcionalidades e

\footnotetext{
${ }^{8}$ Atualmente, no entanto, tem-se debatido sobre o desenvolvimento sustentável que engloba, dentre outros, preocupações relacionadas ao meio ambiente e ao desenvolvimento humano. Preferiu-se abordar exclusivamente o desenvolvimento humano neste trabalho, visto que o tema em análise está diretamente relacionado ao aspecto humano do desenvolvimento, e indiretamente a outros aspectos do desenvolvimento sustentável. 
capacidades adquiridas pelas pessoas - e não exclusivamente por parâmetros econômicos ou pelo acesso a bens primário. As funcionalidades, conforme proposto por Sen (2000a, p.75), correspondem às várias coisas que uma pessoa pode, de acordo com seus valores próprios, fazer ou ser diante de sua situação concreta. Englobam tanto o acesso a bens primários (como alimentos, tratamentos médicos, etc.) quanto aspectos mais complexos, como o senso de pertencimento na sociedade. Estas funcionalidades permitem que o bem-estar seja mensurado de forma inovadora em relação ao pensamento desenvolvimentista clássico: ao invés apenas do Produto Interno Bruto e da renda per capita, também considera fatores sociais. Nesse sentido, o Índice de Desenvolvimento Humano (IDH), concebido com sua a contribuição, é atualmente calculado pelo PNUD, com base em dados referentes à três matrizes: renda per capita, expectativa de vida ao nascer escolaridade (UN, 2019).

As capacidades, por sua vez, referem-se às várias combinações de funcionalidades que as pessoas têm acesso ou têm perspectiva de acessar. Isto é, referem-se às liberdades substantivas que as pessoas têm acesso e que lhes permitem poder escolher seu estilo de vida (SEN, 2000, p. 75). O conceito de capacidade seniano não está relacionado à [in]capacidade física, mental ou cognitiva das pessoas; tem, na verdade, um conceito bastante pragmático: compreende as verdadeiras oportunidades que cada pessoa tem, ou seja, aquilo que as pessoas podem fazer ou ser (e não ter) (MITRA, 2006, p.1). A definição de desenvolvimento humano adotada pela própria ONU no Relatório de Desenvolvimento Humano de 2015 incorpora estes conceitos senianos, já que considera que este seria concomitantemente um meio e um fim ao processo de expansão das escolhas das pessoas sobre como moldarão suas vidas (ou seja, escolha do estilo de vida, da profissão, etc.), sendo o crescimento econômico apenas parte deste processo - mas não o único objetivo (UN, 2015, p. 2).

A teoria das capacidades de Sen é relevante ao tema do Trabalho Decente das PcDs por dois motivos. Em primeiro lugar, é basilar à própria conceituação de Trabalho Decente. Em "Desenvolvimento como Liberdade", considera o trabalho intrinsecamente relacionado à expansão das liberdades das pessoas e à promoção das capacidades das pessoas em geral (200a, 27 e 45). Ao propor o desenvolvimento humano (ao invés do meramente econômico), sua teoria está relacionada à qualidade de vida e de condições de trabalho traz a este uma preocupação qualitativa, que é o fundamento da concepção de Trabalho Decente. Nesse sentido, entende que o trabalho forçado, o trabalho doméstico (comumente executado pelas mulheres sem salário) e até mesmo o trabalho que, embora remunerado, não tenha uma remuneração e condições dignas, não têm o condão de promover desenvolvimento humano (2000a, p. 45, 115, 46, 
respectivamente). Este primeiro aspecto - de que o trabalho é instrumento e finalidade de expansão das capacidades - deve ser o fio condutor da construção da concepção de Trabalho Decente na esfera da regulação, ou seja, do Direito.

Em segundo lugar, embora não use "abordagem social" da deficiência, Sen dialoga com esta: dentro das funcionalidades e capacidades, incorpora aspectos da construção social da deficiência (MITRA, 2006), na medida em que considera que os custos adicionais relacionados à deficiência geram uma "deficiência de conversão" de recursos em liberdades e capacidades (SEN, 2000, p. 88.). Se compararmos pessoas sem deficiência e PcDs que tenham uma mesma renda per capita e estejam inseridas num mesmo contexto geográfico, a PcD terá uma menor conversão de seus recursos financeiros em funcionalidades, em razão dos custos adicionais associados com a deficiência em si (por exemplo, com próteses, medicamentos e tratamentos) em comparação com a pessoa sem deficiência (SEN, 2000a, p. 74). Isso pode gerar menor perspectiva de capacitação profissional, o que afetará a capacidade de escolha de um estilo de vida, já que a $\mathrm{PcD}$ é mais propensa a não acessar um trabalho com maior remuneração. $\mathrm{A}$ deficiência também pode dificultar a conversão em capacidades por outros fatores não relacionados à empregabilidade ou renda, por exemplo, em razão de barreiras físicas causadas pela falta de adaptação arquitetônica ou urbanística que impede a locomoção de cadeirantes em espaços comuns, o que igualmente gera diferença de capacidades com as demais pessoas ${ }^{9}$.

Além disso, em colaboração à própria OIT, Sen (2000b) entende que existe uma relação direta entre Trabalho Decente e expansão dos direitos das pessoas no geral. Mais do que expandir às vagas de trabalho, o papel do Trabalho Decente para Sen seria o de melhorar as condições qualitativas de trabalho, e em especial promover um ambiente de diálogo, em que não apenas as reivindicações dos empregados em geral podem ser ouvidas, mas também as dos grupos comumente marginalizados (200b, p.120). Esse diálogo na qual as necessidades e outras demandas dos grupos minoritários são incluídas é crucial para a expansão e adequação dos direitos e condições de trabalho das PcDs. O autor ainda resgata que o Trabalho Decente não seria um direito da qual nasce um dever ou obrigação perfeita à uma pessoa determinada (por exemplo, o empregador). Diante disso, é possível entender que não seria possível identificar

\footnotetext{
9 Em linha com esta teoria, desde 2001, tem-se a tentativa da adoção da Classificação Internacional das Incapacidades, Funcionalidades e Saúde (CIF) em conjunto com a Classificação Internacional de Doenças (CID), um questionário que busca auferir as condições das funcionalidades e capacidades das pessoas em geral, associadas ou não a alguma doença, para identificar fatores que contribuem à qualidade de vida (DUBOIS e TRANI, 2009, p.197).
} 
com exatidão quais seriam seus elementos ou características especificas, e embora não seja oponível à uma pessoa pré-determinada na lei, é oponível a todos em geral.

Nesse mesmo sentido, a OIT não conceitua precisamente o Trabalho Decente. E, diante do acima, a literatura tem entendido que a concepção de Trabalho Decente não é fechada - ao contrário, seria intencional que seja fluída e possa variar de acordo com as características regionais ou internas de cada Estado-membro da OIT (TRANI e BAKHSHI apud VOSKO, 2002, p. 27). É, certo, no entanto, que este deve ser construído por cada país com base nos quatro objetivos estratégicos e na teoria das capacidades, donde se pode concluir que este tem dupla proteção, quais sejam, qualitativa e quantitativa (ABRAMO, 2010, p. 152). Isto é, deve proteger a expansão das taxas de pleno emprego e a qualidade deste, tendo como ponto focal os quatro objetivos estratégicos: (i) a proteção dos direitos humanos nas relações de trabalho, (ii) a geração de mais e melhores empregos para homens e mulheres, (iii) a extensão da proteção social; e (iv) promoção do tripartidíssimo e dialogo social (ABRAMO, 2010, p. 151).

Evitando uma definição cerrada e admitindo maleabilidade de estabelecimento de modos e metas de cumprimento de 4 objetivos estratégicos - este, sim, precisamente delimitados em seus conteúdos — , a OIT, ao apresentar uma "Agenda de Trabalho Decente" em 1999, destaca o caráter promocional da concepção, desvelado nas iniciativas proativas da Organização na construção de agendas nacionais "customizadas". Tal não significa, contudo, que a concepção de Trabalho Decente não abarque uma dimensão normativa importante, consubstanciadora de seu primeiro objetivo estratégico, qual seja, de proteção dos direitos humanos nas relações de trabalho, em especial aqueles consagrados na Declaração dos Princípios e Direitos Fundamentais do Trabalho de 1998.

Tem, pois, o Trabalho Decente relação direta com a proteção jurídico-normativa aos direitos trabalhistas (SEN, 2000b, p. 124) e outros direitos sociais, na promoção de condições equânimes de oportunidades para homens e mulheres, incluindo PcDs (ABRAMO, 2010, 152). Neste ponto, a não discriminação de qualquer natureza é um dos quatro princípios fundamentais da OIT, estatuídos na Declaração de 1998, e a preservação da integridade física e metal é elemento da qualidade do ambiente de trabalho, que são contemplados pelo primeiro e segundo objetivos estratégicos do Trabalho Decente, respectivamente.

O Trabalho Decente, pois, é um assunto multidisciplinar, relacionado não somente à questões meramente numéricas de trabalho, mas também com a qualidade destes, isto é, às condições aptas a proporcionar a expansão das capacidades e qualidade de vida, daí ter inclusive 
afetação sobre os aspectos psicológicos individuais ${ }^{10}$, bem como ser instrumento à promoção de inclusão social e capacitação das PcDs (TRANI et. al., 2011).

Ainda que a OIT não tenha instrumentos de hard law que consignem um direito subjetivo das PcDs ao Trabalho Decente expressamente, percebe-se que, a partir de 2013, a OIT passou a sugerir melhorias nas condições de trabalho das PcDs em documentos que ora citam o Trabalho Decente, ora o examinam de fato, mas a conexão dos assuntos é ainda embrionária. No entanto, não há qualquer referência ao modelo de deficiência da CIDPCD.

Primeiramente, desde 2001, a OIT tenta criar um indicador comum para aferição do Trabalho Decente (algo semelhante ao IDH), que seja apto a comparar a situação entre os países (ILO, 2008, 2009, 2013). Apesar de a análise de tais indicadores ultrapassar o escopo deste trabalho, e de ainda não existir um consenso sobre tais, a preocupação sobre a situação de trabalho das PcDs se intensificou mais recentemente.

Na assembleia de 2008 (portanto, posterior à Convenção Internacional de Direitos das PcDs da ONU de 2007), a ata da OIT aponta que os indicadores então sugeridos não consideravam as PcDs de forma satisfatória (ILO, 2008, p.23). Em 2013, a assembleia considerou as PcDs, porém, não de forma congruente com o Trabalho Decente, já que foram referidos apenas aspectos quantitativos e não qualitativos. Por exemplo, para aferição do Trabalho Decente, dentro do tópico "condições de oportunidade e tratamento igualitário no trabalho", sugeriu-se apenas considerar a taxa de emprego formal de PcDs, não tendo sido sugerido, por exemplo, a desagregação dessa taxa por sexo, tampouco se auferir as oportunidades que as PcDs têm de ocupar cargos de gerência (ILO, 2013, p. 16). Ora, conforme o Relatório de Desenvolvimento Humano de 2015 (p. 45), tanto em países de alto quanto de baixo rendimento (critério não especificado), as taxas de emprego formal das PcDs são significativamente menores em comparação com as demais pessoas, sendo a situação das mulheres com deficiência acentuada. Nos países de alto rendimento, para cada uma mulher com deficiência empregada haveria dois homens com deficiência empregados; nos países de baixo rendimento, a proporção seria de 1 para 3 (UN, 2015, p. 38).

Além disso, nesta assembleia de 2013, sugeriu-se mensurar Trabalho Decente das PcDs pelos os índices de assistência social (v.g. benefícios que substituam salários para os desempregados e auxílio-doença aos que não forem reabilitados) (ILO, 2013, p. 173). Ora, o Comitê sobre os Direitos das PcDs da ONU condenou o Estado da Espanha por ter considerado

\footnotetext{
${ }^{10}$ Nesse sentido, BLUESTEN et. al. (2016) apontam que o Trabalho Decente é um fator determinante de saúde pública, já que a saúde psicológica seria afetada negativamente pelo desemprego e positivamente pelas condições de trabalho (BLUESTEIN et. al., 2016, p. 4).
} 
que uma pensão monetária por falta de trabalho seria suficiente para promover a dignidade da pessoa (vide Comunicação $n^{\circ}$ 34/2015 adiante). Depois, em 2015, mais uma vez, na definição da Agenda 2030, a ONU segmentou os temas de Trabalho Decente e inclusão de PcDs, sem referenciá-los de forma conexa (ONU, 2015).

Os documentos referenciados denotam que a OIT tangenciou, entre 2008 a 2015, as dificuldades enfrentadas pelas PcDs ao acesso a Trabalho Decente, ainda que deixando de tratar os temas de forma organicamente conexa. Um primeiro documento incipiente sobre o assunto foi feito em 2020, em que a OIT recomendou, expressamente, que os planos de ação dos países em resposta à pandemia de COVID-19 garantissem a inclusão de PcDs no ambiente de trabalho, fazendo uma única referência expressa a Trabalho Decente como forma de assegurar o trabalho com proteção social das $\mathrm{PcDs}^{11}$. $\mathrm{O}$ documento enuncia recomendações relacionadas às condições de trabalho durante a pandemia, dentre as quais auxílio ou benefício financeiro a PcDs que sejam autônomos ou empreendedores, bem como subsídio a quem emprega PcDs, para que o emprego desta seja mantido. Ademais, a OIT também fez especial recomendação para criação de medidas de inclusão de mulheres com deficiência no ambiente de trabalho, já que seriam as mais prejudicadas. O documento, por fim, alude que as ações (e omissões) de tais planos no que tange à inclusão de PcDs no trabalho terão impacto futuro na acessibilidade destas pessoas a uma condição de Trabalho Decente (OIT, 2020).

Além disso, voltando-se às empresas, no "Guia para empresas sobre direitos das pessoas com deficiência" (OIT, 2015), lançado pela OIT em âmbito global em 2015 e, em português, em 2018. explicam-se os direitos das PcDs no âmbito da ONU (CIDPCD de 2007) e da OIT, bem apresentam-se exemplos de medidas patronais e governamentais que podem ser implementadas para a inclusão de PcDs no mercado de trabalho, tais como, sistemas de cotas, iguais oportunidades de admissão e criação de um ambiente de trabalho sem estigmas. Há, ainda, relatos de empresas que conseguiram admitir PcDs (OIT, 2015, p.22 e ss.).

O Estado brasileiro editou, com a cooperação do escritório da OIT no Brasil, a Agenda Nacional do Trabalho Decente, em 2006, que elenca 3 prioridades brasileiras para promoção do Trabalho Decente (BRASIL, 2016). Este documento refere-se às PcDs uma única vez: dentre as ações para a Prioridade 1 (geração de empregos com igualdade de oportunidades e tratamento), prevê ser necessária a "Implementação de programas e ações de combate à discriminação no trabalho, com atenção especial para mulheres, população negra, jovens,

\footnotetext{
${ }^{11}$ Nesse sentido: "It is based on the ILO approach to promoting decent work for all and ensuring employment and social protection for persons with disabilities. Doing so will contribute to each of the ILO's key pillars in fighting COVID-19 in the world of work" (OIT, 2020, p.1). 
idosos, pessoas vivendo com HIV/Aids e pessoas com deficiência" (BRASIL, 2016, p. 10). Em 2010, é lançado o Plano Nacional do Trabalho Decente, que cumpriu a função de detalhar as metas da Agenda Nacional, indicando e quantificando ações e elegendo formas de acompanhamento. Neste Plano não houve qualquer menção a PcDs (BRASIL, 2010).

O Brasil, além de não contar com um índice de Trabalho Decente, também não produziu estudos ou monitoramentos periódicos de indicadores alusivos sobre o assunto. Até o momento, apenas dois relatórios foram editados sobre o assunto e existe apenas uma referência às PcDs. O documento "Perfil do Trabalho Decente no Brasill", de 2009 (referente ao período de 1992 a 2009), emitido pela OIT, apresenta um curto item sobre a situação das PcDs (OIT, 2009). Naquela ocasião, a OIT apontou que, em 2008, 1\% dos trabalhos formais tinham sido ocupados por PcDs, as quais teriam rendimento maior do que as pessoas ditas sem deficiência: o rendimento médio das PcDs remontava a $\mathrm{R} \$ 1.717,00$ mensais, enquanto a média geral a $\mathrm{R} \$$ 1.494,00 (OIT, 2009, p.36). O documento, no entanto, apontou enormes diferenças salariais conforme o tipo de deficiência, sendo que os deficientes mentais teriam o pior rendimento, R\$ 690,00. A empregabilidade das PcDs, contudo, declinou sensivelmente (OIT, 2009, p.52). De acordo com dados da RAIS de 2018 (competência 2017), embora cerca de 6,7\% das pessoas no Brasil sejam consideradas $\mathrm{PcDs}^{12}$, tais ocupam $0,9 \%$ dos postos de trabalho formal e recebem salários inferiores à média geral (BRASIL, 2018).

\section{Proteção do trabalho das PcDs à luz da convenção internacional sobre os direitos das PcDs da ONU}

A Convenção Internacional sobre os Direitos das Pessoas com Deficiência da Organização das Nações Unidas (ONU) (CIDPCD) foi assinada por vários Estados-membros da ONU em 2007, tendo alguns aderido ao Protocolo Facultativo, que reconhece a competência do Comitê de Direitos das Pessoas com Deficiência (Comitê). Por estes instrumentos, há uma

\footnotetext{
${ }^{12}$ Conforme o Censo de 2010, 23,4\% dos residentes no Brasil seriam PcDs, considerando como deficiente quem declarasse ter "[...] pelo menos alguma dificuldade em uma ou mais questões" (Brasil, 2018). Em 2018, por recomendação do Grupo de Washington (órgão mantido pela ONU), os parâmetros internacionais de deficiência passaram a corresponder a quem declarasse ter "[...] pelo menos muita dificuldade em um uma ou mais questões" (Brasil, 2018), o que representa 6,7\% da população brasileira. O IBGE não divulgou, até o momento, os impactos dessa mudança sobre os demais índices e pesquisas censitárias. No presente trabalho, serão mencionados números publicados originalmente pelo IBGE com base nos parâmetros adotados em 2010 (Brasil, 2018). Não foi encontrado nenhum levantamento oficial do número de PcDs em idade economicamente ativa, dado que teria sido importante para comparar com o índice de empregos formais ocupados por PcDs. O RAIS considera como trabalho formal os empregos em empresas privadas e em órgãos públicos, excluindo-se os servidores públicos, isto é, exclui-se o serviço público em regime estatutário.
} 
ruptura paradigmática do conceito médico da deficiência, já que implementam uma abordagem social da deficiência, pelo qual a sociedade é considerada responsável pela criação de barreiras em torno da deficiência ${ }^{13}$. Diferentemente do sistema da OIT em que apenas os sindicatos podem levar à cabo a análise de violação de direitos, de acordo com o artigo 2 do Protocolo Facultativo da CIDPCD, as pessoas físicas podem individualmente fazer comunicações ao Comitê sobre eventuais violações que os Estados-membros tenham cometido contra a concretização dos seus direitos previstos na Convenção, aplicando-se requisitos formais de admissibilidade. Isso inclui também violação aos direitos ao trabalho e emprego (artigo 27 da CIDPCD) cometido por particulares, que não tenham sido remediadas pelo Estado-membro. $\mathrm{O}$ Comitê tem a competência para analisar e decidir sobre estes casos quando o Estado Parte tenha optado por este protocolo e poderá fazê-los recomendações. As decisões do Comitê são vinculativas ao Estado-membro e o descumprimento pode ensejar sanções internacionais.

O artigo 27 da Convenção trata sobre "Trabalho e Emprego" das PcDs. De forma resumida, por este artigo, os Estados Partes reconhecem o direito das PcDs ao trabalho em igualdade de condições das demais pessoas, sendo este direito ao trabalho compreendido como o direito à oportunidade de se manter com um trabalho de sua livre escolha, em ambiente de trabalho aberto, inclusivo e acessível. O artigo 27, ainda, estipula aos Estados que adotem várias medidas para promover o direito ao trabalho igualitário, e um ambiente de trabalho propício, tais como: (i) não discriminação; (ii) condições iguais, justas e favoráveis (inclusive igual remuneração por trabalho de igual valor); (iii) medidas de adaptação razoável; dentre outros. Adicionalmente, o artigo 8, 2, iii, da CIDPCD menciona, dentre os deveres dos Estados, a promoção do reconhecimento das habilidades, méritos e capacidades das PcDs e de sua contribuição ao local de trabalho e ao mercado laboral. E, no artigo 9 refere-se à acessibilidade em geral, aplicável também ao local de trabalho.

A despeito desta Convenção ter sido elaborada no contexto do Sistema Global de Proteção dos Direitos Humanos da ONU, no qual a OIT se insere como agência especializada das Nações Unidas, e conquanto o Trabalho Decente tenha sido adotado pela OIT desde 1999, o texto da Convenção não faz qualquer referência ao Trabalho Decente. Por isso, tenta-se neste item, a partir de casos concretos levados ao Comitê de seguimento da CIDPCD, constatar ou mesmo inferir um diálogo entre o Comitê Internacional sobre Direitos das PcDs da ONU e a OIT, com relação ao Trabalho Decente.

\footnotetext{
${ }^{13}$ No Brasil, a Convenção foi internalizada pelo Decreto ${ }^{\circ}$ 6.949/2009 com força de emenda constitucional, sob a aprovação do quórum especial do artigo $5^{\circ}, \S 3^{\circ}$ da Constituição Federal, no ano de 2009. 
Conforme exposto anteriormente, pelo modelo de deficiência da CIPDCD, há de se entender que a deficiência é resultado da convergência dos aspectos médicos, psicológicos, e sociais da deficiência. Se, por um lado, os fatores sociais e psicológicos da deficiência são materializados através das barreiras, por outro, estas mesmas barreiras podem revelar as funcionalidades e as capacidades adquiridas pelas PcDs. Com base neste modelo (cujo conteúdo já era reconhecido pela literatura antes da Convenção), tem-se empregado a Classificação Internacional de Funcionalidades para fins de aferição das funcionalidades desde $2001^{14}$.

A pesquisa empreendida encontrou 5 comunicações feitas ao Comitê que possuem como objeto a violação à direitos relacionados a "trabalho e emprego" (artigo 27 da Convenção) $)^{15}$. Nenhuma faz referência expressa ao termo "Trabalho Decente", porém, uma faz referência às normas da OIT. O Anexo I contém um resumo de todas as decisões, porém, trazemos em seguida comentários às recomendações do Comitê aos casos em que o mérito (conteúdo trazido) tenha sido analisado ${ }^{16}$.

\section{Comunicação $n^{0}$ 5/2011}

A comunicação foi feita por M. J. L. contra o Estado da Suécia, por violação aos direitos de não discriminação e reconhecimento legal do princípio da igualdade. Em síntese, a autora tem deficiência visual total e havia concorrido a uma vaga de emprego na Assistência Social, tendo sido selecionada em várias entrevistas, sendo que, em determinado momento, precisaria se submeter a uma prova escrita, porém, não pôde fazê-la por faltar tecnologia assistiva. Recorreu administrativamente para que a Assistência Social (na condição de empregadora) adotasse um software para esta prova, sem sucesso.

O Comitê, em análise de requisitos de admissibilidade, recebeu a comunicação. Com relação ao mérito, julgou-o integralmente procedente e entendeu que o Estado da Suécia de fato

\footnotetext{
14 Há, no entanto, uma linha na literatura que entende que a CIF não seria compatível com o modelo biopsicossocial, e tenta criar um novo modelo aplicável às PcDs com base na teoria das capacidades. Conforme DUBOI e TRANIS (2009), por exemplo, a aferição das funcionalidades estaria alinhado com o modelo médico, e propõe uma classificação objetiva de funcionalidades, enquanto que o modelo das capacidades sugerido pelo autor estaria compatível com o modelo biopsicossocial porquanto tem o enfoque nas perspectivas de escolha de estilo vida que têm acesso. No entanto, internacionalmente, tem-se adotado critérios de funcionalidades sobretudo em razão do seu caráter objetivo.

${ }^{15}$ Pesquisou-se a expressão "trabalho-emprego" pré-determinada no diretório de pesquisas da ONU aplicável ao Comitê; tentou-se verificar se há outras decisões em outros organismos da ONU que relacionem "trabalhoemprego" e "deficiente(s)" , sem novos resultados. Para acesso à íntegra destas decisões: https://juris.ohchr.org/search/results. Acesso em janeiro de 2021.

${ }^{16}$ Preferiu-se por não tecer sobre os casos que não foram analisados por falta de requisitos de admissibilidade ou provas, porque o Comitê não adentrou no mérito nestas circunstâncias, sendo seus comentários sobre temas não afetos ao da pesquisa (questões formais ou burocráticas).
} 
cometeu um ato discriminatório ao não prover tecnologia assistiva, bem como que lhe faltava criar normas internas de proteção às PcDs compatíveis à Convenção que incorporassem a abordagem social da deficiência. O Comitê apontou que houve descumprimento direto ao artigo 5 da CIDPCD cujo objeto é "Igualdade e Não-Discriminação", especificamente ao item 3 em razão do Estado da Suécia ter falhado na promoção de "adaptação razoável"17.

Embora não empreste da OIT o uso da concepção de "Trabalho Decente", esta decisão do Comitê dialoga com três dos quatro objetivos estratégicos do Trabalho Decente, notadamente com (i) a proteção dos direitos humanos nas relações de trabalho, (ii) a geração de mais e melhores empregos para homens e mulheres, (iii) a extensão da proteção social, na medida em que reconhece o insucesso do Estado da Suécia em promover condições iguais de oportunidades no processo seletivo de vagas de emprego para PcDs em razão de falta de adaptação razoável através de tecnologia assistiva, já que configura uma violação de direitos humanos das PcDs sobre relações de trabalho, impede a geração de novos empregos para PcDs bem como obsta a proteção social conferida pela própria CIDPCD.

\section{Comunicação n ${ }^{0}$ 5/2010}

L. G. fez a comunicação ao Comitê em 2011, apontando como vítima principal seu filho (cidadania alemã, com deficiência severa desde o nascimento) e os genitores como vítimas secundárias. L. G. alega que o Estado da Alemanha violou vários direitos do seu filho, em especial os elencados no artigo 3, 4, 8, e 27 da Convenção (princípios gerais, obrigações gerais, conscientização e laborais). Apesar de não se referir ao assunto, o Comitê entendeu ser aplicável também o artigo 5 sobre não discriminação.

A autora alega que seu filho não teve assistência para fins de capacitação profissional, tendo frequentado escolas regulares, sendo os auxílios complementares todos custeados pela família, na medida de sua possibilidade financeira. E que, tendo concluído o ensino médio, inscreveu-se como PcD para auxílio vocacional de agência estatal para que pudesse auxiliá-lo na obtenção de um trabalho. No entanto, segundo a autora, a única medida prevista nas normas internas eram a de assistência a pessoas que tenham recebido uma oferta vinculante de trabalho e que sejam acometidas com deficiência temporária, passível de ser superada em no máximo 3 anos, sendo que neste período, os seus empregadores recebem um subsídio de 30\% dos custos com esta PcD. Diante do acima, ingressou com uma ação em âmbito nacional, aguardando a

${ }^{17}$ Conforme o artigo 2 da Convenção, adaptação razoável abrange as modificações e os ajustes necessários e adequados, que não acarretem ônus desproporcional ou indevido, para garantir à igualdade de oportunidades com as demais pessoas. 
autora mais de 3 anos para sua decisão. Nesse período, a agência de Serviço Social perdeu parcialmente o registro do histórico de seus documentos.

Diante do acima, a autora alegou discriminação em matéria laboral de PcDs, em especial pela falta de ensino especial e capacitação profissional especializada, e pela falta de políticas públicas capazes de auxiliar o seu filho (PcD permanente) a ingressar no ambiente de trabalho. Alegou que os órgãos de serviço social não davam suporte à admissão de PcDs em vagas de trabalho; e indicou que os principais obstáculos enfrentados pelas agências de recrutamento para tanto seriam a falta de regulamentação legal sobre os direitos das PcDs e de divisão clara de responsabilidades entre órgãos públicos. A autora, em nome do seu fillho, levou o caso à apreciação do Judiciário alemão, chegando em última instância, sendo os direitos indeferidos, o que lhes trouxe custos para judicialização de seus direitos.

O Estado da Alemanha tentou refutar a autora alegando, dentre outros, que: (i) o fato de a PcD pagar por custos processuais (custas, despesas e honorários advocatícios) não era uma pena ou multa, e que não constituiria violação a direito; (ii) a agência de empregos nunca negou a possibilidade de promover assistência à integralização dos empregados PcDs nos casos em que os requisitos foram atendidos; (iii) a autora não teria esgotado os meios jurídicos internos (requisito de admissibilidade); (iv) o autor (filho da autora) não levou à jurisdição interna qualquer indicação de discriminação que sustentou no âmbito do Comitê.

O Comitê entendeu que a autora atendeu a todos os requisitos de admissibilidade e recebeu a comunicação de violação. Quanto ao mérito (conteúdo), primeiramente, sobre a única medida assistiva à colocação das PcDs no mercado de trabalho, entendeu que a política pública vigente era discriminatória por obstar a fruição de qualquer direito laboral em igualdade, posto que primeiro era concedida sob a condição de que a $\mathrm{PcD}$ tenha recebido uma oferta vinculativa de trabalho e, segundo, que sua deficiência seja superável em até 3 anos. Esta política pública, à luz do Comitê, teria sido elaborada conforme o modelo médico de $\mathrm{PcD}$, já que exclui a perspectiva de trabalho de PcDs cujas deficiências não sejam superáveis ou curáveis. E que, no caso do filho da autora, esta política serviu como impedimento - e não como um incentivo -à contratação de PcDs. Entendeu que a única política pública de inclusão de PcDs ao trabalho adotado pela Alemanha violaria aos princípios gerais da Convenção (artigo 3) e os itens (i) e (j) do Preâmbulo. E, ainda, que a Alemanha violou a sua obrigação de dar acesso à PcDs ao trabalho bem como criar um ambiente de trabalho inclusivo, aberto e acessível, por força do artigo 27 da Convenção. 
Em vista do acima, em 2014, o Comitê condenou o Estado da Alemanha por descumprimento aos artigos 3 (Princípios Gerais), artigo 4 (Obrigações Gerais dos Estados), artigo 5 (Igualdade e Não-discriminação), e artigo 8 (Conscientização). E fez várias recomendações ao Estado da Alemanha, dentre as quais a adequação ao modelo de deficiência da Convenção ${ }^{18}$; envio de relatórios semestrais sobre as suas ações para o cumprimento de sua decisão; tradução da decisão e relatórios ao vernáculo alemão e sua disponibilização em ambientes acessíveis para conhecimento de todos. Mais uma vez, apesar de não fazer referência expressa à OIT, sua decisão retoma de forma clara ao menos três objetivos do Trabalho Decente. Em primeiro lugar, a decisão do Comitê retoma o objetivo de gerar mais e melhores empregos (segundo objetivo), porém, mais do que simplesmente preocupado com a taxa de emprego formal, o Comitê também retoma com a questão qualitativa, em especial com a proteção dos direitos de todas as PcDs na relação de emprego (primeiro objetivo) e extensão da proteção social (quarto objetivo), inclusive as pessoas com deficiência permanente e não reabilitável.

\section{Comunicação no $34 / 2015$}

Esta comunicação foi feita em 2015 por V. F. C., um cidadão catalão contra o Estado da Espanha pela violação por diversos artigos da CIPDCD. O autor era policial e, em razão de um acidente que lhe causou uma deficiência motora permanentemente, foi excluído da ativa. Tentou reintegração para outra função compatível com sua deficiência na esfera administrativa e judicial, tendo sido seu pedido negado em sede recursal por incompatibilidade de sua deficiência com as funções policiais. Seu recurso à corte constitucional foi inadmitido. $\mathrm{O}$ Comitê admitiu a comunicação e, com relação ao mérito, considerou que o Estado da Espanha violou o artigo 27 cumulados com 3, 4 e 5, todos da CIDPCD, ao aplicar uma norma da prefeitura da cidade de Barcelona que impede o exercício de funções adaptadas à PcDs, porquanto determina aos integrantes dos quadros da polícia que tenham adquirido "deficiência total permanente" sejam aposentadas por invalidade mandatoriamente. O Comitê ainda entendeu pela violação do artigo 3 da Convenção (Igualdade e Não Discriminação) pela

\footnotetext{
${ }^{18}$ As recomendações feitas ao Estado alemão foram as seguintes: (i) com relação ao filho da autora: o Estado deveria remediar a violação dos direitos desta $\mathrm{PcD}$ conforme determinados pela Convenção, incluindo a promoção de oportunidades de trabalho, e compensação financeira pelos custos incorridos com o processo judicial e a comunicação ao Comitê; (ii) em geral: considerando que as normas do Estado sobre o assunto eram anteriores à sua ratificação da Convenção, o Estado Alemão deveria revisar a legislação interna para adequá-la aos preceitos da Convenção, e criar políticas públicas para prevenir violações similares, em especial deveria criar políticas públicas voltadas à pessoas com deficiência permanentes.
} 
impossibilidade jurídica de policiais exercerem outros tipos de funções internas, compatíveis com deficiências totais incapacitantes, apesar de existir previsão legal para isso para outras carreiras. Alertou ao Estado que, nos termos do artigo 27 da Convenção, os Estados Partes devem reconhecer o direito das PcDs de manter seu trabalho, em igualdade de condições com as demais pessoas; tomar todas as medidas apropriadas, inclusive por meio de legislação, para proibir a discriminação com base na deficiência no que diz respeito à continuidade do emprego; e garantir que acomodações razoáveis sejam fornecidas a pessoas que adquirem uma deficiência durante o curso do emprego.

Adicionalmente, o Comitê mencionou que o Estado da Espanha teria violado às seguintes Convenções da OIT a qual aderiu anteriormente: (i) Convenção OIT no 111 de 1958 sobre Discriminação em Matéria de Emprego e Ocupação; (ii) Convenção OIT nº 159 de 1983 sobre Reabilitação Profissional e Emprego de Pessoas Deficientes, pelo qual deveria ter tomado medidas para reabilitação profisssional do autor.

O Comitê, ainda, analisou a legislação interna da Espanha, e constatou que existia uma norma de proteção especifica para PcDs elaborada à luz da convenção que estava em fase de promulgação. Comitê, pois, fez uma série de recomendações ao Estado da Espanha: (a) com relação ao autor da demanda, o Estado deveria indenizá-los pelos custos incorridos e promover sua reabilitação profissional; e (b) em geral, deveria tomar medidas para evitar outros episódios de discriminação, dentre os quais: (i) adequação das normas municipais da cidade de Barcelona para que outros policiais possam ser reabilitados; (ii) harmonização das normas internas com os princípios da Convenção. E, ainda, fez outras recomendações sobre monitoramento e publicidade das recomendações.

Nesta decisão é ainda mais evidente a convergência conceitual com a concepção de Trabalho Decente da OIT, porquanto levantada, de um lado, a preocupação com os direitos humanos nas relações de trabalho (primeiro objetivo estratégico), notadamente do direito à manutenção da relação de emprego (segundo objetivo estratégico), neste caso, mediante adaptação razoável. Adicionalmente, de forma bastante ostensiva o Comitê defende o valor dignificante do trabalho e que este não seria substituível por uma compensação monetária, o que evidencia mais um alinhamento com a concepção de Trabalho Decente, especificamente porque tende à expansão da proteção social em sentido amplo (terceiro objetivo estratégico) ao considerar a qualidade dignificamente como intrínseca aos direitos humanos relacionados a emprego e trabalho das PcDs, afastando seu entendimento de uma perspectiva meramente materialista pela qual poder-se-ia concluir que a compensação monetária pela quebra do vínculo 
trabalhista ou pela falta de oportunidades acesso à uma vaga de trabalho seria uma obrigação compensatória suficiente à inclusão social das PcDs.

A partir das comunicações submetidas ao Comitê, é possível identificar que as seguintes barreiras ao direito ao trabalho das PcDs não foram solucionadas no âmbito interno (i) atitudinal: discriminação; (ii) tecnológica: falta de acessibilidade por inexistência de tecnologia assistiva (ii) jurídica: falta de normas internas e políticas públicas adequadas para promover a inclusão social à luz da Convenção. Estas barreiras não são, no entanto, mapeáveis a partir exclusivamente de indicadores como taxas de empregabilidade das PcDs e de percepção de benefícios assistenciais. É possível, no entanto, perceber que embora as decisões do Comitê não emprestem da OIT a concepção de Trabalho Decente, há uma convergência conceitual em suas decisões com os objetivos estratégicos desta concepção, em especial, com três deles, quais sejam, proteção dos direitos humanos nas relações de trabalho, geração de mais empregos, extensão da proteção social.

\section{Conclusão}

O presente trabalho teve como objetivo responder se há convergência conceitual entre a OIT e o Comitê sobre a proteção jurídica ao Trabalho Decente das PcDs. Embora inexista uma norma internacional específica sobre este tema, percebe-se esforços comuns para ampliar a qualidade das condições de trabalho das PcDs.

Em um primeiro momento, a OIT protegeu as pessoas em geral contra discriminação (Convenções da OIT n n 111/1958) e as PcDs conferiu a reabilitação (Convenção OIT $n^{\circ}$ 159/1983), alinhando-se ao modelo médico da deficiência, por isso, o enfoque nas deficiências reabilitáveis. Naquele contexto, não havia esforços para empregabilidade de PcDs não reabilitáveis, tampouco reconhecia-se que a sociedade contribui para a construção da deficiência. A OIT, no entanto, tem ampliado sua preocupação sobre questões qualitativas do trabalho com a discussão de Trabalho Decente, e gradativamente tenta proteger as PcDs. Nesse sentido, os documentos da OIT fazem recomendações direcionando aos Estados-membros para considerar as taxas de empregabilidade e de benefícios assistenciais que as PcDs auferem para fins de Trabalho Decente, ou são instrumentos de conscientização de direitos das PcDs voltados às empresas. De forma pontual, em 2020, a OIT considerou relevante a preocupação com as condições de trabalho das PcDs dentro de um contexto específico, qual seja, de pandemia ocasionada pelo COVID-19, para garantir-lhes futuramente acesso ao Trabalho Decente. 
Apesar deste último documento fazer a única alusão conjunta de conexão direta entre "Trabalho Decente" e "PcDs", nem este nem os demais documentos fazem referência aos problemas levados pelas PcDs ao Comitê.

A CIPCD firmada em 2007 (e internalizada por muitos países até 2009) traz uma proteção normativa às $\mathrm{PcDs}$ sob uma óptica distinta: reconhecendo que a deficiência também é resultado de uma construção social, visa proteger as PcDs em todos os tipos de relações sociais, inclusive trabalhistas, donde todos os esforços para conferir melhores condições de trabalho às PcDs devem ter como núcleo a abordagem social de deficiência consagrado pela CIDPCD.

Apesar das pessoas fisicamente individualmente terem acesso ao Comitê, ele é pouco acionado para casos envolvendo violação ao artigo 27 da CIDPCD (trabalho e emprego). De outro lado, a OIT tem uma abordagem bastante tímida no que tange à inclusão das PcDs na agenda de Trabalho Decente - e, em suas poucas referências ao tema, não faz qualquer alusão ao modelo de deficiência da CIDPCD. Ou seja, cada um dos organismos internacionais usam uma linguagem e adotam fundamentos diferentes sobre as relações de trabalho das PcDs parecendo à primeira vista não terem convergência.

Entende-se ser cedo inferir que o Sistema Global de Proteção dos direitos humanos tenha consignado paradigmas claros aos Estados-membros sobre quais seriam as medidas estatais exigidas em prol das PcD no mercado de trabalho, sendo isso mais uma barreira em desfavor das PcDs. A despeito disso, vislumbra-se que existe espaço para convergência em âmbito de cooperação internacional.

A concepção de Trabalho Decente tal como adotada pela OIT oferece standards hermenêuticos de resolução de casos contenciosos (tanto para avaliação do caso quanto para o estabelecimento de formas de reparação, em caso de condenação) e propositivos para políticas públicas que podem ser úteis para o Comitê. Porém, o sistema de monitoramento da OIT é bem menos acessível às PcDs individualmente do que o da CIDPCD pois as denúncias (chamadas "reclamações") só podem ser oferecidas por sindicatos.

Um diálogo convergente da OIT e do Comitê em torno do Trabalho Decente reforçaria o Comitê como instrumento internacional capaz de oferecer ganhos concretos de efetividade no impulsionamento de avanços na consecução da promoção do Trabalho Decente especialmente, através dos casos concretos levados à sua apreciação. Além disso, é apto a trazer uma especial contribuição por dar ao Trabalho Decente uma construção que incorpore a sociedade como fator construtivo da deficiência, o que não foi tangenciado pela OIT em nenhum momento. 
A partir do texto do artigo 27 da CIDPCD e das decisões do Comitê analisadas percebe-se que seria possível promover uma convergência conceitual com o Trabalho Decente a partir dos objetivos estratégicos mediante o diálogo com três entendimentos Comitê.

O primeiro entendimento do Comitê é de que o trabalho é elemento essencial para o desenvolvimento humano, e à expansão das liberdades e capacidades das PcDs. Nesse sentido, os Estados-membros têm o dever de promover a expansão das capacidades das PcDs, bem como de garantir o reconhecimento da capacidade civil e laboral destas pessoas, por força do artigo 8 da CIDPCD. A Comunicação no 34/2015 (readmissão do policial que fora compulsoriamente aposentado com percepção de aposentadoria) é clara no sentido de que a promoção do trabalho é imprescindível ao desenvolvimento pessoal da $\mathrm{PcD}$, e que a percepção de renda não substitui o direito ao trabalho, alinhando-se aos objetivos estratégicos de direitos humanos nas relações de trabalho, aumento de empregabilidade e proteção social.

Nesse sentido, é possível concluir três pontos paradigmáticos para possível cooperação entre o Comitê e a OIT. Primeiro, este entendimento do Comitê está bastante alinhado com a teoria das capacidades, pelo qual a renda não é considerada como instrumento idôneo para mensuração de funcionalidades nem de capacidades (SEM, 1999 e 2000). E, em segundo lugar, é questionável a manutenção de um sistema que incentive ou considere que a solução para as PcDs seria o recebimento de um benefício assistencial ou indenizatório, em especial nos casos em que a PcD tenha a possibilidade real de ter uma ocupação digna.

Deste segundo também deriva o terceiro: as barreiras enfrentadas pelas PcDs devem ser endereçadas pelo Trabalho Decente. Nesse sentido, com base na CIDPCD, o Comitê tem a função de monitorar a CIDPCD e de decidir casos concretos que versem sobre violações idos direitos das PcDs que, em última análise, transparecem quais são as principais barreiras enfrentadas pelas PcDs em seu país. As decisões analisadas pelo Comitê indicaram que três tipos de barreiras não foram solucionados pelos Estados-parte no âmbito interno, quais sejam, atitudinal (discriminação), tecnológica (acessibilidade) e jurídica (falta de normas internas e políticas públicas). Estas barreiras, reitera-se, não são mapeáveis através de indicadores quantitativos, como por exemplo o monitoramento de taxas de empregabilidade formal e acesso à benefícios assistenciais, como indicado pela OIT para aferição do acesso à Trabalho Decente pelas PcDs.

Embora falte convergência conceitual entre a OIT e o Comitê, o reconhecimento internacional do Trabalho Decente como um objetivo concretizável até 2030 traz esperança de sua proteção normativa internacional, bem como de estendê-la para as PcDs. No entanto, as 
sugestões da OIT de se auferir taxas de empregabilidade e benefícios assistenciais às PcDs, para fins de Trabalho Decente, não são capazes de combater as principais barreiras enfrentadas pelas PcDs que foram levadas ao Comitê descritas acima. Além disso, os documentos da OIT têm sido direcionados à melhorias de condições de trabalho das PcDs, que representam apenas parte das barreiras enfrentadas pelas PcDs para acesso a postos de trabalho com direitos assegurados sem discriminação e de qualidade, pilares da concepção de Trabalho Decente, tendo sido excluída da agenda, por exemplo, a barreira jurídica levantada pelo Comitê. Conforme recomendado pelo Comitê nas três comunicações analisadas, os Estados-membros deveriam adequar suas normas internas ao modelo da CIDPCD, donde se entende que a existência de instrumentos de hard law é relevante para criar aos Estados-membros o dever de cumprimento interno dos direitos das PcDs e de políticas para sua efetivação.

Considerando que a CIDPCD e o Comitê trouxeram uma ruptura com o modelo médico da deficiência, parece-nos que o ponto nucelar dos esforços da OIT e do Comitê sobre matérias relacionadas ao trabalho das PcDs devem ser empenhados de forma a conectar o Trabalho Decente com a abordagem social de deficiência da CIDPCD, pelo qual a sociedade é vista como agente da criação de barreiras para a inclusão de PcDs em diversos âmbitos, inclusive no laboral. Em termos concretos, significa criar mecanismos para quebrar as barreiras que forem sendo mapeadas pelo Comitê, ainda que os não o façam de forma conjunta. Além disso, embora a pandemia ocasionada pelo COVID-19 tenha afetado significativamente a vida e as relações de trabalho de todas as pessoas e tenha colocado o Trabalho Decente em debate em especial porque até o momento (2021) diminuiu as taxas de emprego formal, colocou pessoas como dependentes de rendas inferiores (redução de salário, seguro-desemprego ou assistência) e àqueles que puderam continuar trabalhando estão sujeitos às piores condições de trabalho -, é importante que a OIT e o Comitê mantenham em sua agenda a preocupação com Trabalho Decente das PcDs de forma permanente. As circunstâncias lamentáveis de vida e trabalho das PcDs ocasionadas pela pandemia quiçá serão temporárias e cessarão junto com o vírus, porém, as barreiras que estas pessoas enfrentam são renovadas e prolongadas pela sociedade e, por isso, carecem ser a principal preocupação da OIT e do Comitê para garantir o Trabalho Decente às PcDs - daí ser de suma relevância o diálogo contínuo entre ambos. 